\title{
Outcomes of Cardiac Resynchronization Therapy in Heart Failure Patients and Effect of MAGGIC-HF Score on Prognosis
}

\section{(D) Gökay Nar1, (1) Sara Çetin2, (1) Gürsel Şen1, (1) Güven Günver3}

\author{
1Pamukkale University Faculty of Medicine, Department of Cardiology, Denizli, Turkey \\ ${ }^{2}$ Servergazi State Hospital, Clinic of Cardiology, Denizli, Turkey \\ 3̇̇stanbul University, İstanbul Faculty of Medicine, Department of Biostatistics, İstanbul, Turkey
}

\begin{abstract}
Objectives: Cardiac resynchronization therapy (CRT) has recently become a significant treatment option in patients with heart failure (HF), who do not respond to optimal medical treatment. In this study, we aimed to evaluate the long-term prognosis of CRT and to determine the relationship between the Meta-Analysis Global Group in Chronic Heart Failure (MAGGIC-HF) risk score and CRT.

Materials and Methods: One hundred and ten consecutive patients who underwent CRT between 2015 and 2019 were analyzed retrospectively. Baseline characteristics of the patients were recorded and clinical parameters including laboratory, electrocardiographic and echocardiographic were compared before CRT implantation and during patient follow-up. The patients were classified as surviving patients and patients without survival according to the 2-year clinical outcome. The improvement in echocardiographic parameters observed at the $6^{\text {th }}$ month after CRT in surviving patients was defined as a positive response to CRT.

Results: The patients with survival had lower pulmonary artery systolic pressure (PASP) ( $34.66 \pm 18.31$ vs $46.50 \pm 15.86$ $\mathrm{p}=0.01)$ and higher left ventricular ejection fraction (LVEF) than patients without survival $(27.00 \pm 5.86$ vs $23.89 \pm 5.32$ $\mathrm{p}=0.04)$. After 6 months from CRT implantation, the improvement of LVEF and PASP and decrease in left ventricular
\end{abstract}

\footnotetext{
Address for Correspondence: : Gökay Nar, Pamukkale University Faculty of Medicine, Department of Cardiology, Denizli, Turkey e-mail: gokay_nar@yahoo.com ORCID: orcid.org/0000-0001-6159-7785

Received: 22.11.2020 Accepted: 26.01.2021

Cite this article as: Nar G, Çetin S, Şen G, Günver G. Outcomes of Cardiac Resynchronization Therapy in Heart Failure Patients and Effect of MAGGIC-HF Score on Prognosis. EJCM 2021;9(1):9-18.
}

DOI: 10.32596/ejcm.galenos.2020-11-064

${ }^{\circ}$ Copyright 2021 by Heart and Health Foundation of Turkey (TÜSAV) / E Journal of Cardiovascular Medicine published by Galenos Publishing House. 


\section{Abstract}

diameters were found in patients with survival $(\mathrm{p}=0.015)$. In addition, there was a weak correlation between MAGGIC risk score levels and hospitalizations in this study population $(\mathrm{p}=0.031, \mathrm{r}=208)$

Conclusion: Predictors of long-term survival in CRT treatment are basal LVEF and PASP levels. Basal LVEF is important in the positive response to CRT.

Keywords: Cardiac resynchronization therapy, heart failure, prognosis

\section{Introduction}

Heart failure (HF) is still an important health problem today. Despite the positive improvements in treatment, it is associated with poor prognosis and mortality ${ }^{(1)}$. Cardiac resynchronization treatment (CRT) is one of the invasive treatment methods widely used in patients with HF in recent years, and many studies have shown that CRT is an effective treatment method for increasing quality of life and functionality and improving survival. CRT is recommended for patients with unresponsiveness to medical treatment, poor New York Heart Association (NYHA) functional class, left ventricular ejection fraction (LVEF) $<35 \%$ and QRS duration $\geq 130 \mathrm{~ms}^{(2,3)}$. However, the benefit required from CRT may not be seen in $1 / 3$ of the patients. Therefore, it is important to identify patients who will not benefit from CRT due to high cost-effectiveness ${ }^{(4)}$. Before CRT implantation, examining the clinical-demographic characteristics of patients who respond positively to CRT and evaluating echocardiographic, electrocardiographic and laboratory parameters may play an important role in the selection of candidates for this treatment. In addition, various HF risk models may be used to determine the survival after CRT and positive response to CRT in patients with HF. One of these risk models is the MAGGIC-HF (Meta-Analysis Global Group in Chronic Heart Failure) risk score model developed by the Global Group of Meta-Analysis, which can be used in HF patients with both reduced ejection fraction and preserved ejection fraction ${ }^{(5)}$. In this study, we aimed to determine the positive response to CRT and predictors affecting survival and to evaluate the prognostic significance of the MAGGIC risk score calculated before CRT.

\section{Materials and Methods}

\section{Study Population}

This retrospective observational study was carried out with HF patients who underwent CRT implantation at Pamukkale University Medical Faculty Hospital between January 2015 and January 2019. CRT was applied to patients with LVEF $<35 \%$ and NYHA class II-III and Iva, who were resistant to optimal medical therapy in the last 3 months, with a QRS duration $\geq 130 \mathrm{~ms}$ in Left bundle branch block (LBBB) morphology or a QRS duration $\geq 150$ ms without LBBB morphology. Before CRT, the MAGGIC-HF risk scores of the patients were calculated and the NYHA functional class was determined by at least 2 experienced cardiologists who were blind to the study. HF was classified in three groups, as ischemic, nonischemic and other causes according to the underlying etiology. Ischemic HF was defined as HF due to a previous myocardial infarction and severe coronary artery disease with or without intervention. The clinical and demographic characteristics, comorbidities, medications, preoperative and post-operative indicators of the patients and the data collected during the follow-up visits were recorded and stored for later analysis. However, patients who could not be followed up according to the data obtained from the records or who had a lack of data were excluded from the study and finally, the study was carried out with 110 patients. 
The subjects were classified as patients with survival within the first 2 years after CRT (group 1, n=91) and patients without survival (group 2, $n=19$ ). Patients who survived after CRT were divided into two subgroups as those who responded positively to CRT (group 1a, $\mathrm{n}=44$ ) and those who did not (group $1 \mathrm{~b}, \mathrm{n}=47$ ) and a $10 \%$ increase in LVEF after the CRT procedure was defined as a positive response ${ }^{(6)}$. Preoperative clinical data including laboratory, electrocardiographic and echocardiographic parameters and MAGGIC-HF risk scores of the groups were compared to determine the positive response to CRT and factors affecting survival. Preoperative and postoperative six-month periods of the patients with survival were reanalyzed to determine which parameters were associated with the positive response to CRT.

This study was approved by Pamukkale University Faculty of Medicine Hospital Denizli, Turkey Ethics Review Board in accordance with the Declaration of Helsinki (decision no: 60116787-020/34161, date: 09.06.2020), and informed consent was obtained from all registered patients.

\section{CRT Implantation}

The left ventricle pacing was implanted into the lateral or posterolateral vein after the coronary sinus was cannulated with a guide sheath using the left subclavian approach. The right atrial lead was placed in the right atrial appendage and the right ventricular lead was placed in the right ventricular apex or right ventricular outflow tract. Fluoroscopy was used to evaluate the final position of the left ventricular pacing lead, and optimization of device parameters before discharge was provided for each patient.

\section{Clinical Data}

Peripheral venous blood samples of the patients were collected for standard blood tests after 8-12 hours of fasting. The resting electrocardiogram data of the patients before and after CRT implantation and during followup were analyzed. The QRS duration was defined as the longest measured QRS time in any lead. 2D transthoracic echocardiographic imaging was performed with Vivid 7 GE echocardiography device before and after CRT implantation. Left atrial diameter, left ventricular end diastolic diameter (LVEDD) and left ventricular end systolic diameter (LVESD) were measured using the M-mode method. LVEF was calculated by the bi-plane Simpson method and pulmonary artery systolic pressure (PASP) was calculated by the modified Bernoulli equation by adding the estimated right atrial pressure to the tricuspid regurgitation jet flow velocity.

\section{Clinical Outcomes}

The mortality due to HF and all causes within two years after CRT implantation was defined as the primary outcome. The improvements in echocardiographic parameters after CRT implantation were defined as the secondary outcome.

\section{Statistical Analysis}

The analysis of all data was performed using SPSS v.21.0 for Windows (SPSS, Inc., Chicago, Ill., USA). Continuous variables were expressed as mean \pm standard deviation and categorical variables were expressed as frequency and percentage. The Shapiro-wilk test was used to check the normality of continuous data, the student's t-test for variables that were compatible with normal distribution, and the Mann-Whitney $U$ test for variables not compatible with normal distribution. Comparison of categorical variables was performed by the chi-square analysis and the statistical significance level (alpha) was considered as 0.05 .

\section{Results}

\section{Baseline Demographic and Clinical Characteristics of the Study Population}

Baseline demographic and clinical characteristics of the groups are shown in Table 1. There are no significant differences in mean age, distribution of gender and comorbidities such as hypertension, diabetes, coronary artery diseases, cerebrovascular diseases and chronic 
Table 1. Baseline characteristics of study population

\begin{tabular}{|c|c|c|c|}
\hline Variables & Group $1(n=91)$ & Group 2 (n=19) & p-value \\
\hline \multicolumn{4}{|l|}{ Demographics } \\
\hline Mean age, (years) & $62.43 \pm 12.46$ & $63.89 \pm 7.93$ & 0.630 \\
\hline Body mass index $\left(\mathrm{kg} / \mathrm{m}^{2}\right)$ & $29.70 \pm 3.80$ & $29.60 \pm 4.00$ & 0.766 \\
\hline \multicolumn{4}{|l|}{ HF characteristics } \\
\hline Non ischemic HF, n (\%) & $16(16)$ & $4(21)$ & 0.558 \\
\hline Other causes of HF, n (\%) & $21(25)$ & $4(21)$ & 0.721 \\
\hline NYHA II, n (\%) & $11(12)$ & $1(5)$ & 0.418 \\
\hline NYHA III, n (\%) & $76(84)$ & $16(84)$ & 0.566 \\
\hline Hypertension, n (\%) & $67(74)$ & $12(63)$ & 0.546 \\
\hline Diabetes, n (\%) & $32(35)$ & $7(37)$ & 0.763 \\
\hline Dyslipidemia, n (\%) & $34(37)$ & $4(21)$ & 0.218 \\
\hline Current smoking, n (\%) & $29(32)$ & $5(26)$ & 0.732 \\
\hline COPD, n (\%) & $5(5)$ & - & 0.309 \\
\hline Previous stroke, n (\%) & $3(3)$ & $1(5)$ & 0.641 \\
\hline CAD, n (\%) & $70(77)$ & $13(68)$ & 0.669 \\
\hline \multicolumn{4}{|l|}{ Laboratory } \\
\hline Creatinine, $(\mathrm{mg} / \mathrm{dL})$ & $1.14 \pm 0.43$ & $1.28 \pm 0.46$ & 0.23 \\
\hline LVESD, (mm) & $53.01 \pm 8.80$ & $56.78 \pm 10.36$ & 0.11 \\
\hline PASP, $(\mathrm{mmHg})$ & $34.66 \pm 18.31$ & $46.50 \pm 15.86$ & 0.01 \\
\hline \multicolumn{4}{|l|}{ Medications } \\
\hline Beta blockers, n (\%) & $82(90)$ & $16(84)$ & 0.866 \\
\hline ACEI/ARB/ARNI, n (\%) & $75(82)$ & $14(73)$ & 0.642 \\
\hline Aldosterone antagonist, $\mathrm{n}(\%)$ & $70(77)$ & $14(74)$ & 0.899 \\
\hline Other diuretics, n (\%) & $58(63)$ & $12(63)$ & 0.855 \\
\hline Anti-aggregants, n (\%) & $66(64)$ & $14(74)$ & 0.645 \\
\hline Statins, n (\%) & $41(45)$ & $6(32)$ & 0.359 \\
\hline Digitalis, n (\%) & $23(25)$ & $5(26)$ & 0.824 \\
\hline Ivabradine, n (\%) & $16(18)$ & $4(21)$ & 0.642 \\
\hline \multicolumn{4}{|l|}{ Electrocardiogram } \\
\hline Sinus rhythm, n (\%) & $74(81)$ & $15(79)$ & 0.840 \\
\hline
\end{tabular}


Table 1. continued

\begin{tabular}{|c|c|c|c|}
\hline Atrial fibrillation, n (\%) & $17(19)$ & $3(16)$ & 0.840 \\
\hline QRS duration >150 msn, $\mathrm{n}(\%)$ & $28(31)$ & $5(26)$ & 0.801 \\
\hline QRS duration $>130$ msn, $\mathrm{n}(\%)$ & $63(67)$ & $13(68)$ & 0.845 \\
\hline RBBB morphology, n (\%) & $2(2)$ & $2(11)$ & 0.066 \\
\hline MAGGIC score & $24.41 \pm 5.70$ & $25.06 \pm 4.70$ & 0.650 \\
\hline
\end{tabular}

obstructive pulmonary diseases. ( $>>0.05)$ Also, the laboratory findings, electrocardiographic parameter, medications, HF properties such as duration, etiology and NYHA functional class did not show significant differences in HF patients with survival and without survival. ( $p>0.05$ ) However, LVEF was significantly higher and PASP was significantly lower in patients with survival compared to patients with no survival. (LVEF, $27.00 \pm 5.86,23.89 \pm 5.32, \mathrm{p}=0.04$; PASP, 34.66 \pm 18.31 , $46.50 \pm 15.86, \mathrm{p}=0.01$, respectively). Also, the MAGGIC risk score did not differ between the groups ( $\mathrm{p}>0.05$ ).

\section{Comparison of the Preoperative and Postoperative 6-month Periods of Patients with Survival After CRT}

Comparing the patients with a positive response to CRT (group 1a) and those without (group 1b), the negative response to CRT was shown more frequently in patients with a history of DM and hyperlipidemia and previous pacemaker/implantable cardioverter defibrillator (ICD) history. In addition, the patients who responded positively to CRT had higher LVEF (31.57 $\pm 9.25,25.96 \pm 5.99$; $\mathrm{p}<0.001)$ (Table 2).

When the 6-month periods before and after CRT of the surviving patients were compared, it was found that LVEDD, LVESD, and PASP decreased and LVEF increased in the $6^{\text {th }}$ month, and the improvements in these parameters were statistically significant $(\mathrm{p}=0.015)$ (Figure 1-4). In the two-year follow-up after CRT implantation, the mean hospitalization time was 1 day and there was a

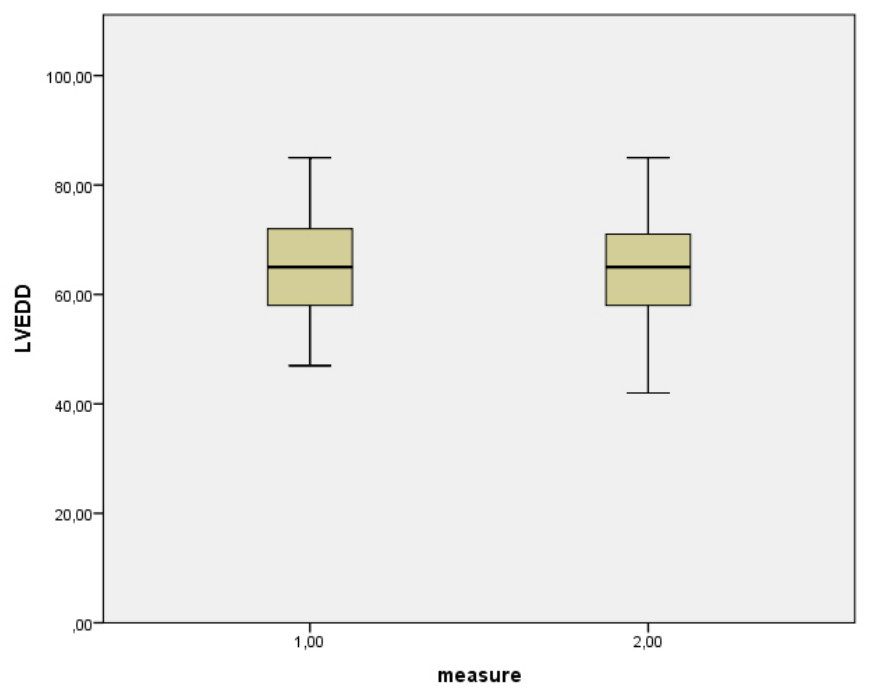

Figure 1. Comparison of preoperative and postoperative 6-month LVEDD measurements of survival patients LVEDD: Left ventricular end diastolic diameter

significant but weak correlation between the MAGGICHF risk score and re-hospitalizations $(\mathrm{p}=0.031, \mathrm{r}=208)$ (Table 3).

\section{Discussion}

The regression in LVDD, LVSD, PASP and the increase in LVEF were the parameters showing CRT positive response in this study. The two main determinants of survival in CRT were preoperative PASP level and basal LVEF. The MAGGIC-HF risk score was insufficient to predict prognosis in the post-CRT period. Among the surviving patients, patients who responded positively 


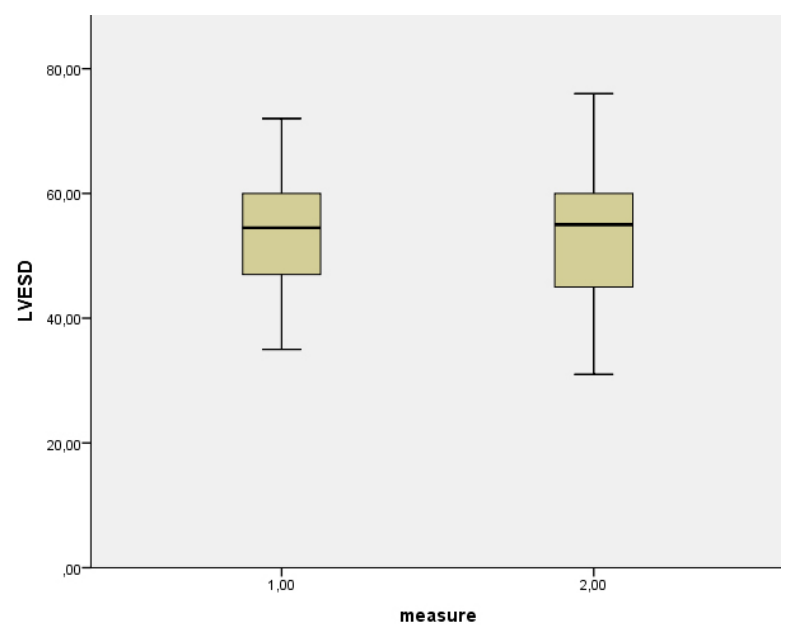

Figure 2. Comparison of preoperative and postoperative 6-month LVESD measurements of survival patients

LVESD: Left ventricular end systolic diameter

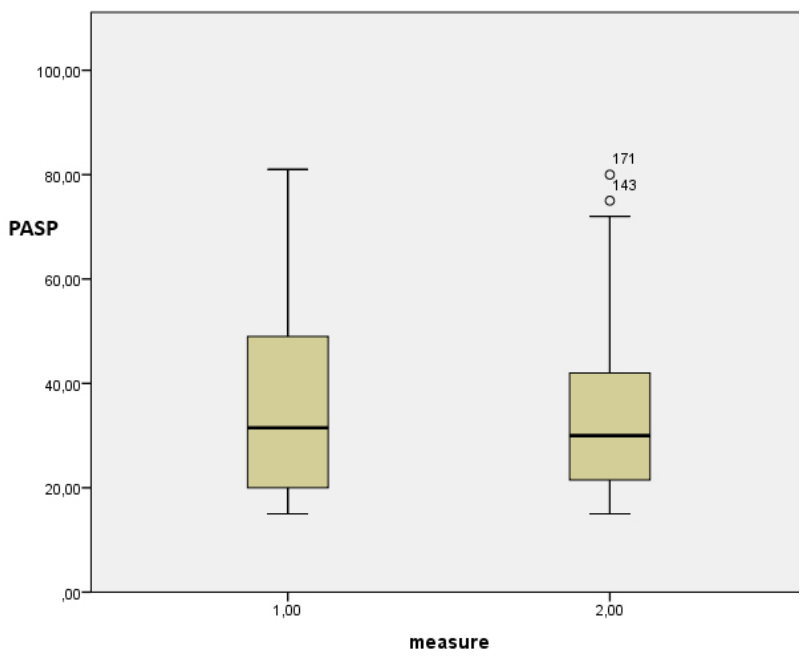

Figure 3. Comparison of preoperative and postoperative 6-month PASP measurements of survival patients

PASP: Pulmonary artery systolic pressure

to CRT had less DM, hyperlipidemia and pacemaker implantation. Besides, basal LVEF was higher in patients who responded positively to CRT.

CRT implantation improves prognosis in patients with HF. However, the randomized controlled studies have shown that the mortality is between $15 \%$ and $18 \%$ in the 12-24 month period after CRT and this rate increases more in longer periods ${ }^{(7)}$. Low LVEF is still associated with increased mortality, and basal LVEF should be considered

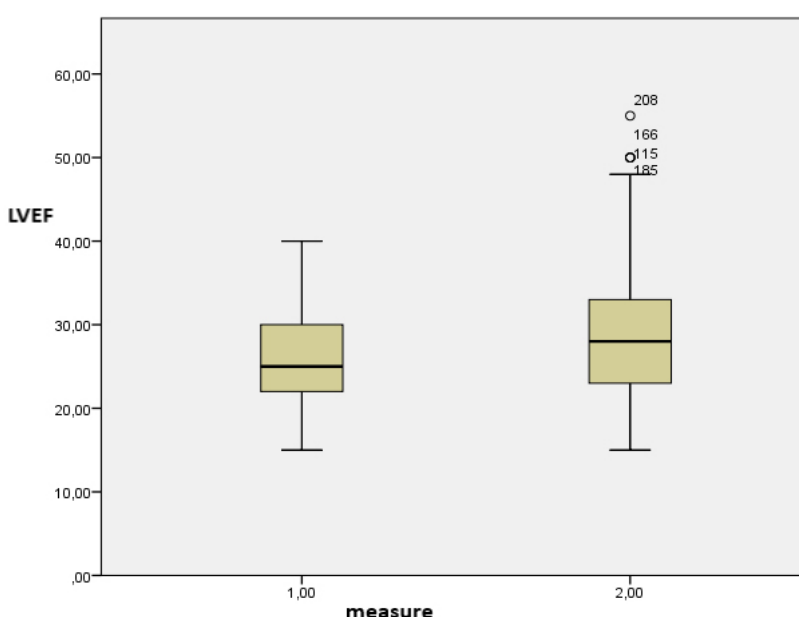

Figure 4. Comparison of preoperative and postoperative 6-month LVEF measurements of survival patients

LVEF: Left ventricular ejection fraction

to determine candidates for CRT implantation ${ }^{(8)}$. Small previous studies have shown that patients with severe symptoms but higher baseline LVEF exhibit better clinical and echocardiographic improvement ${ }^{(9,10)}$. In the MADITCRT study, patients were classified into three groups as $<25 \%, 26-30 \%$ and $>30 \%$ according to LVEF, and the group with the lowest LVEF had high mortality ratio and recurrent HF. Although the clinical benefit seen from CRT was independent of basal LVEF, the group with LVEF $>30 \%$ provided more improvements from $\mathrm{CRT}^{(11)}$. In our study, similar to randomized controlled studies, the two-year mortality rate was $17 \%$. In our study, one of the important parameters for survival and positive response to CRT was basal LVEF and the patients with high LVEF showed a more positive response to CRT. However, PROSPECT and REVERSE studies have suggested that the clinical and echocardiographic benefit seen from CRT is independent of LVEF, unlike the MADIT-CRT study and our study ${ }^{(12,13)}$. The contradictory results obtained from the studies may base on the different definitions of the patients included in the study, like clinical and demographic characteristics or positive response to CRT, the differences of NYHA functional class, and inclusion criteria. 
Table 2. Baseline characteristics of the study population with CRT responses

\begin{tabular}{|c|c|c|c|}
\hline Variables & Group 1a $(n=44)$ & Group 1b $(n=47)$ & p-value \\
\hline \multicolumn{4}{|l|}{ Demographics } \\
\hline Mean age, (years) & $60.24 \pm 11.50$ & $63.86 \pm 11.95$ & 0.250 \\
\hline Male gender, n (\%) & $28(64)$ & $36(77)$ & 0.140 \\
\hline Body mass index $\left(\mathrm{kg} / \mathrm{m}^{2}\right)$ & $28.20 \pm 3.50$ & $29.00 \pm 4.40$ & 0.824 \\
\hline \multicolumn{4}{|l|}{ HF characteristics } \\
\hline HF duration, week & $44.70 \pm 25.10$ & $50.20 \pm 27.50$ & 0.362 \\
\hline Ischemic HF, (n) \% & $23(52)$ & $31(66)$ & 0.191 \\
\hline Non ischemic HF, n (\%) & $9(20)$ & $7(15)$ & 0.731 \\
\hline Other causes of HF, n (\%) & $12(27)$ & $9(19)$ & 0.264 \\
\hline NYHA II, n (\%) & $6(14)$ & $5(11)$ & 0.892 \\
\hline NYHA III, n (\%) & $38(86)$ & $41(87)$ & 0.922 \\
\hline NYHA IVa, n (\%) & 0 & $1(2)$ & 0.899 \\
\hline ICD/Pacemaker history, n (\%) & $1(2)$ & $6(13)$ & 0.030 \\
\hline \multicolumn{4}{|l|}{ Comorbidities } \\
\hline Hypertension, n (\%) & $30(68)$ & $37(79)$ & 0.446 \\
\hline Diabetes, n (\%) & $9(20)$ & $23(49)$ & 0.006 \\
\hline Dyslipidemia, n (\%) & $8(18)$ & $26(55)$ & 0.004 \\
\hline Current smoking, n (\%) & $12(27)$ & $17(36)$ & 0.710 \\
\hline COPD, n (\%) & $2(5)$ & $3(6)$ & 0.522 \\
\hline Previous stroke, n (\%) & $2(5)$ & $1(2)$ & 0.410 \\
\hline CAD, n (\%) & $33(75)$ & $37(79)$ & 0.864 \\
\hline \multicolumn{4}{|l|}{ Laboratory } \\
\hline Creatinine (mg/dL) & $1.17 \pm 0.47$ & $1.14 \pm 0.40$ & 0.720 \\
\hline BUN (mg/dL) & $22.45 \pm 9.42$ & $25.20 \pm 13.74$ & 0.240 \\
\hline Sodium (mEq/L) & $137.96 \pm 4.09$ & $137.88 \pm 2.64$ & 0.906 \\
\hline C reactive protein (mg/L) & $1.15 \pm 1.79$ & $1.18 \pm 1.79$ & 0.940 \\
\hline \multicolumn{4}{|l|}{ Echocardiographic } \\
\hline LVEF (\%) & $31.57 \pm 9.25$ & $25.96 \pm 5.99$ & $<0,001$ \\
\hline LVEDD (mm) & $65.24 \pm 8.56$ & $64.96 \pm 8.31$ & 0.87 \\
\hline LVESD (mm) & $53.49 \pm 9.23$ & $54.15 \pm 8.92$ & 0.71 \\
\hline PASP (mmHg) & $36.88 \pm 18.95$ & $36.89 \pm 18.19$ & 0.96 \\
\hline \multicolumn{4}{|l|}{ Medications } \\
\hline Beta blockers, n (\%) & $39(89 \%)$ & $41(87 \%)$ & 0.514 \\
\hline ACEI/ARB/ARNI, n (\%) & $34(77 \%)$ & $41(87 \%)$ & 0.497 \\
\hline Aldosterone antagonist, $\mathrm{n}(\%)$ & $37(84 \%)$ & $33(70 \%)$ & 0.899 \\
\hline Other diuretics, n (\%) & $27(61 \%)$ & $31(66 \%)$ & 0.894 \\
\hline Anti-aggregants, n (\%) & $28(64 \%)$ & $38(81 \%)$ & 0.070 \\
\hline Statins, n (\%) & $15(34 \%)$ & $26(55 \%)$ & 0.05 \\
\hline Digitalis, n (\%) & $14(32 \%)$ & $9(19 \%)$ & 0.88 \\
\hline Ivabradine, n (\%) & $10(23 \%)$ & $6(13 \%)$ & 0.124 \\
\hline
\end{tabular}

\section{Electrocardiogram}


Table 2. continued

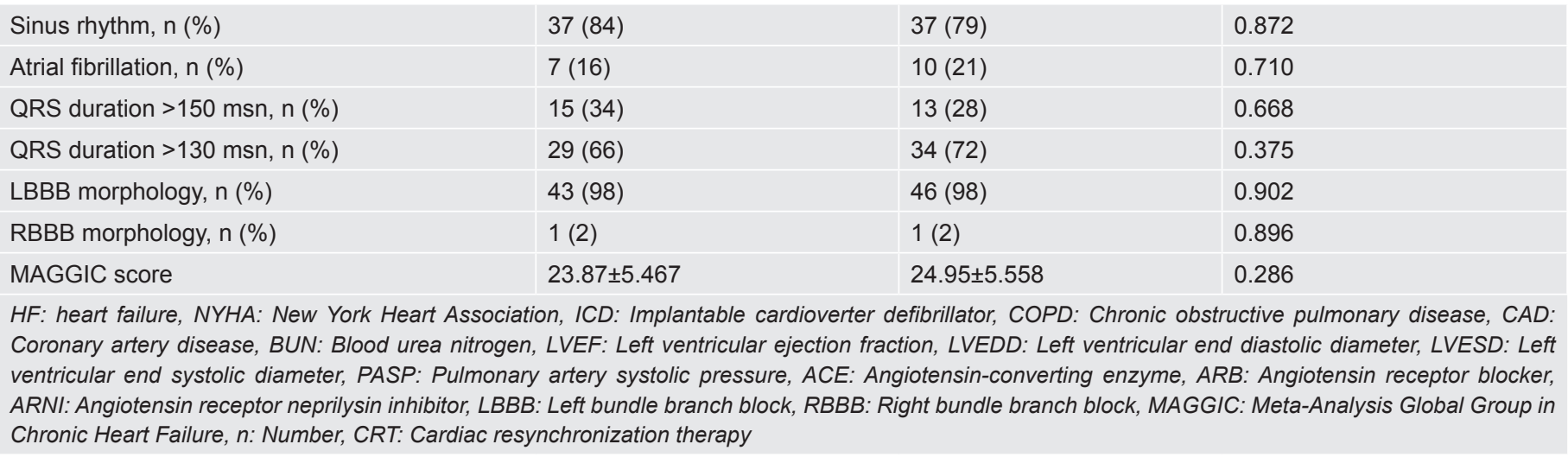

Table 3. Relationship between MAGGIC risk score and hospitalization in surviving patients

\begin{tabular}{|c|c|c|c|}
\hline & & MAGGIC risk score & Hospitalization day \\
\hline \multirow{3}{*}{ Hospitalization } & Pearson correlation & 0.208 & 1 \\
\hline & Sig. (2-tailed) & 0.031 & - \\
\hline & $\mathrm{n}$ & 108 & 108 \\
\hline
\end{tabular}

In patients with a positive response from CRT, at the end of the first month, LVDD, LVSD and left ventricle volumes decrease and this improvement continues up to 12 months in approximately $65-75 \%$ of the patients. In the MIRACLE and Multicentre InSync ${ }^{\mathrm{TM}}$ Randomized Clinical Evaluation-Implantable Cardioverter Defibrillator (MIRACLE-ICD) studies, a significant increase in LVEF was observed with a decrease in left ventricular end systolic-diastolic volume and linear diameters in the patient group with $\mathrm{CRT}^{(14)}$. In our study, similar to the MIRACLE and MIRACLE-ICD studies, there was a significant decrease in LVDD and LVSD and a significant increase in LVEF, and these results were evaluated as a positive response to CRT in patients with survival. The clinical response of HF patients to CRT may differ. Yu et al. ${ }^{(15)}$ could not identify the association of left ventricular end-systolic volume (LVESV) reduction after CRT with NYHA functional class, quality of life, and 6-minute walk test, but in another study, a decrease of $<15 \%$ in LVESV resulted in better clinical improvement ${ }^{(16)}$. However, this situation may associate with placebo effects of CRT.
Therefore, we did not include clinical improvement indicators after CRT implantation to avoid a subjective evaluation in our study. In the REVERSE study, it was shown that the ratio of re-hospitalization was decreased and the hospitalization's duration was shortened after $\mathrm{CRT}^{(17)}$. Similar to this study, the hospitalization's duration was average of one day in our study.

Several studies have shown that the factors such as impaired renal function, presence of AF, poor NYHA functional class, gender, HF etiology, presence of LBBB and QRS duration $>150 \mathrm{~ms}$ affect CRT response and prognosis ${ }^{(18,19)}$. However, Ghanem et al. ${ }^{(20)}$ did not find any relationship between demographic-clinical variables and CRT response. Similar to this study, there was no relationship between demographic-clinical variables with CRT response and clinical outcome in our study.

The increased PASP and right ventricular dysfunction have also been associated with adverse clinical outcomes after CRT $^{(21)}$. Previous studies have shown that patients with PASP levels higher than $50 \mathrm{mmHg}$ have a worse prognosis. However, little is known about how it affects 
the long term after CRT. In a study, Bašinskas et al. ${ }^{(22)}$ classified the patients as PASP $<50 \mathrm{mmHg}$ and PASP $>50$ mmHg before CRT implantation and evaluated their CRT response and survival. As a result, the group with higher PASP levels had more deaths and re-hospitalizations. In another study, PASP levels above $39.5 \mathrm{mmHg}$ were associated with increased mortality after CRT, but this result was not confirmed by Cox regression analysis ${ }^{(22,23)}$. In our study, similar to these studies, one of the important parameters affecting survival and CRT positive response was increased PASP levels and it was closely related to mortality. The decline of PASP was considered as CRT positive response in our study, but this result may be secondary to the improvement of left ventricular functions.

Although various HF risk score models have been developed to evaluate prognosis, to predict survival, and to determine who will benefit from organ transplantation or assist support devices in patients with HF, their reliability is poor on the patient basis and their performance is limited in the estimation of prognosis ${ }^{(24)}$. We used the MAGGIC risk score, which is one of the HF risk score models, in this study. We showed that MAGGIC score did not provide sufficient long-term prognostic information in HF patients.

\section{Study Limitations}

This study had some limitations. This study was designed as a retrospective study and had a relatively small sample. Also, the alterations of HF therapy followup may affect the clinical outcome and CRT response in patients. Other limitations included not using modern echocardiographic parameters such as tissue doppler and strain imaging, which are more sensitive and specific, and not evaluating functional mitral regurgitation, which is one of the CRT response indicators.

\section{Conclusion}

The strongest predictors of survival in patients implanted with CRT are basal LVEF and PASP. Furthermore, basal LVEF is one of the most important factors in the benefit seen from CRT regardless of underlying HF etiology. However, multi-center, randomized controlled large studies are needed to determine candidate patients for CRT and to see long-term results of CRT.

\section{Ethics}

Ethics Committee Approval: This study was approved by Pamukkale University Faculty of Medicine Hospital Denizli, Turkey Ethics Review Board in accordance with the Declaration of Helsinki (decision no: 60116787 020/34161, date: 09.06.2020).

Informed Consent: Informed consent was obtained from all registered patients.

Peer-review: Externally peer-reviewed.

\section{Authorship Contributions}

Surgical and Medical Practices: G.N., G.Ş., Concept: G.N., G.Ş., Design: G.N., G.Ş., Data Collection or Processing: G.N., G.Ş., Analysis or Interpretation: S.Ç., G.G., Literature Search: G.N., S.Ç., Writing: G.N., S.Ç., G.Ş., G.G.

Conflict of Interest: No conflict of interest was declared by the authors.

Financial Disclosure: The authors declared that this study received no financial support.

\section{References}

1. Alpman A. Heart failure old dominant, new friend: beta blockers. Ankara Üniversitesi Tıp Fakültesi Derg 2000;53:43-7.

2. Bektaşoğlu G, Yılmaz MB, Tandoğan İ. The role of echocardiography in cardiac resynchronization therapy. Cumhuriyet Tip Derg 2009;31:316-30.

3. Moss AJ, Hall WJ, Cannom DS, et al. Cardiac-resynchronization therapy for the prevention of heart-failure events. N Engl J Med 2009;361:1329-38.

4. Fuganti C, Melo CS, Moraes Jr AV et al. Diretriz: Terapia de Ressincronização Cardíaca. Relampa 2015;28:1-25.

5. Rich JD, Burns J, Freed BH, Maurer MS, Burkhoff D, Shah SJ. MetaAnalysis Global Group in Chronic (MAGGIC) Heart Failure Risk Score: Validation of a Simple Tool for the Prediction of Morbidity and Mortality in Heart Failure With Preserved Ejection Fraction. J Am Heart Assoc 2018;7:009594.

6. Shantha G, Mentias A, Venkata N, et al. Role of obstructive sleep apnea on the response to cardiac resynchronization therapy and all-cause mortality Heart Rhythm. 2018;15:1283-8. 
7. Verhaert D, Grimm RA, Puntawangkoon C, et al. Long-term reverse remodeling with cardiac resynchronization therapy: results of extended echocardiographic follow-up. J Am Coll Cardiol 2010;55:1788-95.

8. Woo GW, Petersen-Stejskal S, Johnson JW, Conti JB, Aranda JA Jr, Curtis $\mathrm{AB}$. Ventricular reverse remodeling and 6-month outcomes in patients receiving cardiac resynchronization therapy: analysis of the MIRACLE study. J Interv Card Electrophysiol 2005;12:107-13.

9. Fung JW, Zhang Q, Yip GW, Chan JY, Chan HC, Yu CM. Effect of cardiac resynchronization therapy in patients with moderate left ventricular systolic dysfunction and wide QRS complex: a prospective study. J Cardiovasc Electrophysiol 2006;17:1288-92.

10. Foley PW, Stegemann B, Smith RE, Sanderson JE, Leyva F. Cardiac resynchronization therapy in patients with mildly impaired left ventricular function. Pacing Clin Electrophysiol 2009;32:186-9.

11. Kutyifa V, Kloppe A, Zareba W, et al. The influence of left ventricular ejection fraction on the effectiveness of cardiac resynchronization therapy: MADIT-CRT (Multicenter Automatic Defibrillator Implantation Trial With Cardiac Resynchronization Therapy). J Am Coll Cardiol 2013;61:936-44.

12. Chung ES, Katra RP, Ghio S, et al. Cardiac resynchronization therapy may benefit patients with left ventricular ejection fraction $>35 \%$ : a PROSPECT trial substudy. Eur J Heart Fail 2010;12:581-7.

13. Linde C, Daubert C, Abraham WT, et al. Impact of ejection fraction on the clinical response to cardiac resynchronization therapy in mild heart failure. Circ Heart Fail 2013;6:1180-9.

14. Melek M, Esen ÖB, Esen AM, Barutçu İ. Resynchronization Therapy in Heart Failure. Türk Kardiyol Dern Arş 2004;32:376-89.

15. Yu CM, Bleeker GB, Fung JW, et al. Left ventricular reverse remodeling but not clinical improvement predicts long-term survival after cardiac resynchronization therapy. Circulation 2005;112:1580-6.

16. Lafitte S, Reant P, Zaroui A, et al. Validation of an echocardiographic multiparametric strategy to increase responders patients after cardiac resynchronization: a multicentre study. Eur Heart J 2009;30:2880-7.
17. Daubert C, Gold MR, Abraham WT, et al. Prevention of disease progression by cardiac resynchronization therapy in patients with asymptomatic or mildly symptomatic left ventricular dysfunction: insights from the European cohort of the REVERSE (Resynchronization Reverses Remodeling in Systolic Left Ventricular Dysfunction) trial. J Am Coll Cardiol 2009;54:1837-46.

18. van Bommel RJ, Borleffs CJ, Ypenburg C, et al. Morbidity and mortality in heart failure patients treated with cardiac resynchronization therapy: influence of pre-implantation characteristics on long-term outcome. Eur Heart J 2010;31:2783-90.

19. European Society of Cardiology (ESC); European Heart Rhythm Association (EHRA), Brignole M, Auricchio A, Baron-Esquivias G, et al. 2013 ESC guidelines on cardiac pacing and cardiac resynchronization therapy: the task force on cardiac pacing and resynchronization therapy of the European Society of Cardiology (ESC). Developed in collaboration with the European Heart Rhythm Association (EHRA). Europace 2013;15:1070118.

20. Ghanem MT, Allam LE, Ahmed RS. Cardiac resynchronization therapy in patients with heart failure and moderately reduced ejection fraction: Could it trigger a super-response? Indian Heart Journal 2019;71:229-34.

21. Scuteri L, Rordorf R, Marsan NA, et al. Relevance of echocardiographic evaluation of right ventricular function in patients undergoing cardiac resynchronization therapy. Pacing Clin Electrophysiol 2009;32:1040-9.

22. Bašinskas P, Stoškute N, Gerulytė A, Abramavičiūtè A, Puodžiukynas A, Kazakevičius T. Prognostication of Poor Survival After Cardiac Resynchronization Therapy. Medicina (Kaunas) 2020;56:19.

23. Wang D, Han Y, Zang H, et al. Prognostic effects of pulmonary hypertension in patients undergoing cardiac resynchronization therapy. J Thorac Dis 2010;2:71-5.

24. Canepa M, Fonseca C, Chioncel O, et al. Performance of Prognostic Risk Scores in Chronic Heart Failure Patients Enrolled in the European Society of Cardiology Heart Failure Long-Term Registry. JACC Heart Fail 2018;6:452-62. 